REVIEW

\title{
Quality of life in thyroid eye disease: impact of quality of care
}

\author{
Stephanie Estcourt ${ }^{1}$, Anthony G Quinn ${ }^{2}$ and Bijay Vaidya ${ }^{1}$ \\ ${ }^{1}$ Departments of Endocrinology and ${ }^{2}$ Ophthalmology, Royal Devon and Exeter Hospital, Exeter EX2 5DW, UK \\ (Correspondence should be addressed to B Vaidya; Email: bijay.vaidya@pms.ac.uk)
}

\begin{abstract}
Thyroid eye disease (TED) is a chronic debilitating condition causing physical discomfort, facial disfigurement and impaired visual function. The physical consequences of TED could have a negative and lasting impact on patients' employment, hobbies and psychosocial function. In this review, we assess the evidence of the impact of TED on patients' quality of life (QOL) and also explore the effects of suboptimal quality of care on QOL of patients with this disease. It is hoped that recent initiatives, including the Amsterdam declaration, to raise the quality of care for patients with TED will help to improve their QOL.
\end{abstract}

European Journal of Endocrinology 164 649-655

\section{Introduction}

Thyroid eye disease (TED) is a chronic autoimmune disorder usually associated with Graves' disease, although it may also be rarely present in patients with autoimmune hypothyroidism and in patients who are euthyroid $(1,2)$. Patients with TED often suffer with physical discomfort due to pain, grittiness, excessive watering and photophobia. Periorbital swelling, eyelid retraction, conjunctival redness, proptosis and squint can cause distressing facial disfigurement. Furthermore, diplopia caused by the involvement of extraocular muscles and rarely loss of sight due to corneal scarring or optic nerve compression may lead to disabling visual impairment. The physical discomfort, facial disfigurement and impaired visual function associated with TED could have a major impact on patients' employment, hobbies and psychosocial function.

This review is aimed at assessing the evidence of the impact of TED on patients' quality of life (QOL). In addition, we also aim to explore the effects of quality of care on QOL of patients with TED.

\section{Search strategy}

We searched the Medline, CINAHL, PsychINFO, EMBASE and BNI databases, using the key words TED, Graves' ophthalmology, Graves' orbitopathy, visual impairment, QOL, facial disfigurement, quality of care and health care. We also reviewed references of the retrieved papers. We limited our search to Englishlanguage print journals.

\section{Assessment of QOL in TED}

We identified 20 original studies with the primary aim of assessing the impact of TED on patients' QOL (3-22). These could be broadly classified as studies using i) general health-related QOL questionnaires, ii) vision-specific QOL questionnaires, iii) disease-specific QOL questionnaires and iv) qualitative methodology with semi-structured interviews.

\section{Studies using general health-related QOL questionnaires}

QOL studies using general health-related questionnaires in TED are shown in Table 1. In 1997, Gerding et al. (3) published the first study to systematically assess QOL in patients with TED. In this study, 70 consecutive euthyroid patients with varying severity of TED attending a specialist centre in The Netherlands self-administered two validated general health-related QOL questionnaires, the medical outcomes study 24-item short form health survey (MOS SF-24) and three subscales of the sickness impact profile (SIP). Compared with a healthy American reference population, patients with TED were found to have lower MOS SF-24 scores showing negative perceptions of general and mental health as well as physical, social and role functioning. In addition, the QOL scores in patients with TED were found to be worse than those in patients with diabetes, emphysema and heart failure and were comparable to those in the patients with inflammatory bowel disease. It is interesting to note that, although a subgroup of four patients with most 
Table 1 Studies using general health-related questionnaires to assess QOL among patients with TED.

\begin{tabular}{|c|c|c|c|c|}
\hline Study & Country & Study populations & Measurements of QOL & Main outcomes \\
\hline (3) & Netherlands & $\begin{array}{l}\text { TED }(n=70), \text { healthy } \\
\text { reference population } \\
(n=2595), \operatorname{IBD}(n=268), \\
\text { diabetes }(n=844), \\
\text { emphysema }(n=731) \text { and } \\
\text { heart failure }(n=297)\end{array}$ & MOS SF-24 and SIP & $\begin{array}{l}\text { Lower QOL scores compared with a } \\
\text { healthy reference population and } \\
\text { patients with diabetes, emphysema } \\
\text { and heart failure }\end{array}$ \\
\hline (6); (4) & Germany & $\begin{array}{l}\text { TED }(n=102) \text { and healthy } \\
\text { reference population } \\
(n=2914)\end{array}$ & $\begin{array}{l}\text { MOS SF-36, LES, } \\
\text { HADS and WCCL }\end{array}$ & $\begin{array}{l}\text { Lower QOL scores compared with a } \\
\text { healthy reference population. } \\
\text { Increased prevalence of anxiety, } \\
\text { depression and negative life events }\end{array}$ \\
\hline (5) & Germany & $\begin{array}{l}\text { TED }(n=102), \text { T1DM } \\
(n=102) \text { and IBD } \\
(n=102)\end{array}$ & $\begin{array}{l}\text { MOS SF-36, LES, } \\
\text { HADS and WCCL }\end{array}$ & $\begin{array}{l}\text { Lower QOL scores compared with } \\
\text { healthy reference population and } \\
\text { patients with T1DM }\end{array}$ \\
\hline (7) & USA & $\begin{array}{l}\text { TED }(n=24) \text { and } \\
\text { controls }(n=24)\end{array}$ & POMS & $\begin{array}{l}\text { Greater emotional distress than the } \\
\text { control group }\end{array}$ \\
\hline (8) & Poland & $\begin{array}{l}\text { TED }(n=29) \text { and } \\
\text { controls }(n=53)\end{array}$ & MOS SF-36 & $\begin{array}{l}\text { Lower QOL scores compared with } \\
\text { controls }\end{array}$ \\
\hline (9) & Germany & TED $(n=250)$ & $\begin{array}{l}\text { Occupational disability } \\
\text { questionnaire }\end{array}$ & $\begin{array}{l}\text { High prevalence of temporary or } \\
\text { permanent occupational disability }\end{array}$ \\
\hline (10) & South Korea & $\begin{array}{l}\text { TED }(n=49) \text { and } \\
\text { controls }(n=48)\end{array}$ & MOS SF-36 and BDI & $\begin{array}{l}\text { Lower QOL scores compared with } \\
\text { controls. Higher depression scores in } \\
\text { patients with sight-threatening TED }\end{array}$ \\
\hline (11) & Sweden & $\begin{array}{l}\text { Graves' disease randomised } \\
\text { to antithyroid drugs or } \\
\text { radioiodine }(n=308)\end{array}$ & MOS SF-36 & $\begin{array}{l}\text { Low QOL scores in patients with new } \\
\text { development or worsening of TED } \\
\text { irrespective of treatment for Graves' } \\
\text { disease }\end{array}$ \\
\hline
\end{tabular}

BDI, beck depression inventory; HADS, hospital anxiety and depression scale; IBD, inflammatory bowel disease; LES, life experience survey; MOS-24, medical outcomes study 24-item short form health survey; MOS SF-36, medical outcomes study 36-item short form health survey; POMS, profile of mood states; QOL, quality of life; SIP, sickness impact profile; TED, thyroid eye disease; WOCC, ways of coping checklist.

severe TED had the worst QOL scores, the study did not find a correlation between the QOL scores and the duration, clinical activity or severity of TED, suggesting that the patients' perceptions of their eye disease do not necessarily confer with the clinical assessment of health care professionals.

Kahaly et al. (4) using the medical outcome study 36-item short form health survey (MOS SF-36) questionnaire, found lower QOL scores in the 102 German patients with TED compared with a large German reference population. Furthermore, they also demonstrated that $45 \%$ of the patients suffered from anxiety, depression or both, and $72 \%$ experienced one or more negative life events involving professional issues, financial difficulties or family conflicts in the six months prior to the diagnosis of TED. The same group, in a subsequent study, found lower QOL scores in patients with TED compared with those with type 1 diabetes (5). In contrast to Gerding et al. (3), the German study found correlations between the QOL scores and activity and severity of TED. Similar correlations were also shown in two smaller studies; Farid et al. (7) found that patients with moderate to severe TED show a greater emotional distress than those with no or mild TED, and Lee et al. (10) found higher depression scores in patients with sight-threatening TED. In contrast, Kulig et al. (8) did not find a correlation between the QOL scores and severity or activity of TED, although patients with TED were found to have lower QOL scores than controls.

The effect of TED on patients' QOL was also highlighted by a recent study, which examined QOL in 308 patients with Graves' disease randomised to antithyroid drugs or radioiodine (11). It showed reduced QOL scores in patients with new development or worsening of TED, irrespective of the treatment modalities. Finally, Ponto et al. (9) highlighted a profound impact of TED on patients' employment and livelihood in a study, which showed that over one-quarter of patients attending their multi-disciplinary TED clinic suffered from temporary or permanent occupational disability.

Despite the use of different tools (Table 1), the studies using general health-related QOL questionnaires have consistently shown poor QOL as well as increased anxiety and depression in patients with TED. As these tools are designed to assess general perceptions of QOL, they are useful in comparing QOL in different patient groups. Indeed, these studies were able to demonstrate that patients with TED have reduced QOL compared with general healthy population and patients with other chronic conditions. However, the general health-related QOL questionnaires are often too generalised and may miss some of the specific consequences of TED impacting on patients' well-being. This may explain the lack of correlation between the QOL scores and the severity of TED in some studies. 


\section{Studies using vision-specific QOL questionnaires}

A study conducted by Bradley et al. (12) used the National Eye Institute Visual Function Questionnaire (NEI VFQ-25) to assess QOL in 30 patients with mild to severe TED. The NEI VFQ-25 was originally developed to measure the impact of chronic eye diseases on QOL. The study showed a moderately impaired QOL in patients with TED, which was particularly worse in those with diplopia. However, with semi-structured interviews, when the patients were asked to provide feedback about the questionnaire, two-thirds reported that the questionnaire lacked items relating to issues that were important to them, such as ocular discomfort, altered appearance and impact on social and work life.

\section{Studies using disease-specific QOL questionnaires}

General health-related QOL questionnaires are often too broadly based and insensitive to measure subtle yet clinically significant impact of the disease. In contrast, a disease-specific questionnaire is targeted to assess the impact of a specific condition on patients' well-being. Studies using disease-specific QOL questionnaires in TED are shown in Table 2. Terwee et al. (13) developed the first TED-specific QOL tool, the Graves' ophthalmopathy-QOL (GO-QOL) questionnaire.
This tool consists of 16 questions focussing on two specific consequences of TED - visual impairment due to double vision or decreased visual acuity (eight questions) and psychosocial effects of facial disfigurement (eight questions). This and the subsequent studies from the same group found that it is a highly reliable tool to assess QOL in patients with TED, showing good correlations with clinical manifestations of TED and with the general health-related QOL questionnaires, MOS SF-24 and SIP (13-16). Furthermore, the longitudinal validity of the tool was supported by the changes in the scores following different treatments for TED, such as orbital decompression and radiotherapy (15). In a study of 168 patients with longstanding TED, Terwee et al. (16) also found that patients with TED have greatly reduced QOL scores several years after completion of the treatment.

The GO-QOL, which was originally developed in the Dutch language, has been translated into several languages and used in different countries. The GO-QOL in the English, Italian, German, French, Greek and Russian languages can be downloaded from the European Group on Graves' Orbitopathy (EUGOGO) website (http://www.eugogo.eu/eugogo_download_ questionnaire.html. Accessed on 23 February 2011). Park et al. (17) used an English language translation of the GO-QOL on an Australian cohort of patients with TED. They carried out a number of modifications in the

Table 2 Studies using disease-specific questionnaires to assess QOL among patients with TED.

\begin{tabular}{|c|c|c|c|c|}
\hline Study & Country & Study population & $\begin{array}{l}\text { Measurement } \\
\text { of QOL }\end{array}$ & Main outcomes \\
\hline (13) & Netherlands & TED $(n=70)$ & GO-QOL & $\begin{array}{l}\text { Development of a disease-specific } \\
\text { QOL questionnaire }\end{array}$ \\
\hline (14) & Netherlands & TED $(n=93)$ & GO-QOL & $\begin{array}{l}\text { Demonstration of cross-sectional } \\
\text { validity and reliability of the } \\
\text { GO-QOL }\end{array}$ \\
\hline (15) & Netherlands & $\begin{array}{l}\text { TED }(n=164) \text { undergoing } \\
\text { different treatments }\end{array}$ & GO-QOL & $\begin{array}{l}\text { Demonstration of changes in the } \\
\text { GO-QOL scores after different } \\
\text { treatments for TED, supporting } \\
\text { longitudinal validity of the tool }\end{array}$ \\
\hline (16) & Netherlands & $\begin{array}{l}\text { TED after treatment } \\
(n=168), \text { TED before } \\
\text { treatment }(n=70), \text { TED } \\
\text { during treatment } \\
(n=206) \text { and TED } \\
\text { mixed group }(n=93)\end{array}$ & GO-QOL & $\begin{array}{l}\text { Negative impact of TED on QOL } \\
\text { many years after completion of } \\
\text { treatment }\end{array}$ \\
\hline (17) & Australia & TED $(n=128)$ & Modified GO-QOL & $\begin{array}{l}\text { Demonstration of profound adverse } \\
\text { effect of TED on QOL }\end{array}$ \\
\hline (18) & Germany & $\begin{array}{l}\text { TED treated with orbital } \\
\text { decompression } \\
(n=105)\end{array}$ & $\begin{array}{l}\text { Disease-specific QOL } \\
\text { questionnaire }\end{array}$ & $\begin{array}{l}\text { Development of a disease-specific } \\
\text { QOL questionnaire. Demonstration } \\
\text { of improvement in the QOL scores } \\
\text { after orbital decompression }\end{array}$ \\
\hline (19) & USA & $\begin{array}{l}\text { TED }(n=256) \text { and healthy } \\
\text { volunteers }(n=33)\end{array}$ & GO-QLS & $\begin{array}{l}\text { Development of a disease-specific } \\
\text { QOL questionnaire. Significant } \\
\text { impairment of social and vocational } \\
\text { functioning in patients with TED }\end{array}$ \\
\hline (20) & Iran & TED $(n=61)$ & Modified GO-QOL & $\begin{array}{l}\text { Improvement in the GO-QOL scores } \\
\text { after corticosteroid therapy }\end{array}$ \\
\hline
\end{tabular}

GO-QLS, graves' ophthalmopathy quality of life scale; GO-QOL, graves' ophthalmopathy quality of life questionnaire; QOL, quality of life; TED, thyroid eye disease. 
GO-QOL to make it applicable to an Australian group of patients. They replaced a question about the impact of TED on cycling by two questions on effects of TED at work and on carrying out domestic duties and added two more new questions on the effects of education and counselling on QOL. The study confirmed the negative impact of TED on patients' QOL due to impaired visual functioning and reduced self-confidence. This version of GO-QOL was recently translated into Persian and studied on an Iranian cohort of patients with TED pre- and post-corticosteroid therapy (20). This study also found low QOL scores in patients with TED, which showed improvement after corticosteroid treatment. The modified version of GO-QOL has not been validated.

In addition to the GO-QOL, two other disease-specific QOL questionnaires have been developed and studied in patients with TED. Tehrani et al. (18) designed a TEDspecific questionnaire in German, which has 26 questions and 90 items. The questionnaire was studied on 105 patients, with TED undergoing orbital decompression, and was found to have moderate reliability based on an analysis of the Cronbach $\alpha$ coefficient. The study showed a correlation between the QOL scores and proptosis, and over $70 \%$ of patients reported improved QOL scores after orbital decompression surgery. In the USA, Yeatts (19) developed the Graves' ophthalmopathy quality-of-life scale (GO-QLS), another TED-specific questionnaire with 105 questions. The tool was studied on 256 patients with TED after validation in 33 healthy volunteers. The study found that TED significantly impairs social and vocational functioning. There was also a correlation between the QOL scores and the severity of TED, in particular the presence of optic neuropathy. Compared with the GO-QOL, the length of these two disease-specific QOL questionnaires is the major obstacle for their use in routine clinical practice.

A disease-specific QOL questionnaire could be invaluable in clinical research studies for providing information, additional to traditional clinical measures of TED. Indeed, recent clinical trials investigating the effects of different treatment modalities for TED are increasingly using a disease-specific QOL questionnaire as one of the outcome measures (23-25). A disease-specific QOL questionnaire could also have a role as a supporting tool to plan management for individual patients with TED; however, currently, there is no evidence to show that such an approach improves outcome.

\section{Studies using qualitative methodology}

Although in general, vision-specific and disease-specific questionnaire-based studies have consistently shown a negative impact of TED on patients' QOL, the use of predetermined questions in these studies often precludes in-depth exploration of patients' perceptions of well-being. Such in-depth capturing of patients' lived experiences can be achieved with qualitative studies using emergent questions. Our recent qualitative study involving in-depth semi-structured interviews with 25 patients identified the phenomenon of an altered identity as a direct consequence of TED (21). This phenomenon often led to social withdrawal, isolation and low self-esteem, with a profound negative impact on patients' well-being, coping strategies and interactions with health care professionals. These observations are consistent with similar studies in other conditions involving facial disfigurement and chronic disability, which have revealed the emergence of a damaged sense of identity as a result of disease processes (26).

In another study, Watt et al. (22) carried out semistructured interviews followed by structured interviews to identify issues relevant to patients with different thyroid disorders, including 17 patients with TED. They also interviewed 13 physicians to analyse whether there was a concurrence of issues thought to be relevant by patients and physicians. The study showed that both patients with TED and physicians regarded eye symptoms (such as grittiness in eyes, eyelid swelling, blurred vision and pressure in the eyes) as important issues, whereas psychological issues (such as getting stressed, emotional lability and restlessness) were considered more important by patients than by physicians. Interestingly, dissatisfaction with appearance was considered a more important issue by physicians than patients in the study.

\section{Quality of care impacting on QOL in patients with TED}

Although the effect of debilitating clinical manifestations and complexity surrounding the treatment of TED on patients' physical and psychological wellbeing has been well recognised $(27,28)$, the impact of quality of care on these patients' QOL is less discussed. Several surveys of patients with TED and health care professionals involved in the management of this disease have shown evidence for shortcomings in the provision of quality of care, which could contribute to the patients' poor QOL $(21,29-33)$. A recent nationwide survey of patients with TED in the United Kingdom has revealed delays in diagnosis, wide variability in access to specialist centres and appropriate treatment and overall low patient satisfaction with treatment (30). More than half of the patients in the study were initially given incorrect diagnoses for their eye symptoms, and for more than a quarter of the patients, it took longer than a year for the correct diagnosis of TED to be made. The study also found that only a quarter of the patients were referred at a specialist TED clinic and the referrals were often late. This observation is consistent with a European survey of clinicians showing that less than two-thirds had an access to a specialist clinic for TED 
(32). Evidence for the delay in referral to a specialist TED clinic was also found by a study of the EUGOGO centres showing a median time lapse of 16 months from the onset of symptoms of TED to the assessment at the centres (34), and a study from a specialist centre showing that three-quarters of patients referred to the centre had the disease for more than a year (35). These are important observations as a prompt assessment and timely immunosuppressive therapy, if indicated, are critical for achieving a good outcome in TED.

Several studies suggest that patients with TED often have negative experiences when interacting with health care professionals. A qualitative study showed that patients with TED often find it hard to engage in clinical decision-making processes and developing trust and confidence in health care professionals (21). This is consistent with the findings of a survey of patients with TED in the United Kingdom, which showed that only about half of the patients in the survey were satisfied with the treatment they received for TED (30). Remarkably, only a quarter of the patients in the survey felt that they had been helped to cope with the psychological impact of TED (30). An important cause of this negative experience is the disparity between health care professionals' assessment of severity of TED and patients' perception of impact of the disease (3, 4, 36). It is noteworthy that even minor ocular involvement from the physician's standpoint could substantially affect patients' QOL. In a study using photographic slides of 100 patients with varying severity of TED, Terwee et al.(2003) (36) showed that physicians, compared with patients, tend to underestimate the severity of facial disfigurement caused by the disease. Furthermore, in the contemporary health care culture, there is an increasing shift in viewing the patient as an equal partner in their care and promoting patient empowerment by providing information, involving them in clinical decision making and prioritising clinical decisions based on their needs rather than professional expectations. However, many patients with TED do not perceive to experience this at present $(21,30)$. Therefore, although the incidence and severity of TED is decreasing in the recent years, possibly as the result of an earlier diagnosis and treatment of Graves' disease, the quality of care for patients with TED still remains suboptimal.

\section{Improving quality of care for patients with TED}

Recent years have witnessed several important initiatives to improve quality of care for patients with TED. To address deficiencies in the quality and parity of care given to patients with TED, the EUGOGO has developed evidence-based consensus statement for best practice in the assessment and treatment of TED (37). The consensus recognises the value of psychological care, identifies that even mild TED can have a profoundly negative effect on psychosocial functioning and acknowledges the need for careful assessment of patients' QOL in order to determine suitable treatment. It also highlights the importance of rehabilitative surgery in patients with inactive TED and recommends that very long duration of TED is not a contra-indication for rehabilitative surgery. This is highly relevant as Bartley et al. (38) found that over one-third of patients with TED remained unhappy with the appearance of their eyes 10 years after treatment, and rehabilitative surgery could be critical in restoring self-esteem and psychosocial functioning in such patients.

It is increasingly recognised that assessment and management of TED can be complex and best carried out by a specialist multidisciplinary team $(39,40)$. In addition to endocrinologists and ophthalmologists, the specialist multidisciplinary team could include specialist nurses, orthoptists and occupational therapists. As TED can have a profound negative impact on psychosocial functioning and self-esteem, an access to input from professional counsellors, psychologists or psychiatrists in addition to the basic psychological support provided by the physician, specialist nurse or patient support organisation - could be invaluable for some patients. A multi-disciplinary specialist TED clinic could present an ideal environment for assessing not only physical care and treatment but also provide a vital opportunity to evaluate emotional and psychological needs. There is evidence that patients attending a specialist TED clinic are more likely to be satisfied with the treatment for their TED (30). Thus, a key recommendation of the EUGOGO consensus is that all patients with TED, except for the mildest cases, should be referred to a specialist TED clinic (37).

A momentous initiative to improve quality of care for patients with TED is recent signing of the Amsterdam declaration (41). In October 2009, representatives of 82 professional and patient-led organisations all around the world endorsed the declaration pledging to improve QOL of patients with TED by enhancing quality of their care (42). The declaration has set specific 5-year targets, which include raising awareness of the TED, establishing referral and care pathways, timely treatment of patients in centres of excellence and promoting audit and research. It is hoped that the Amsterdam Declaration will have a similar success in raising the profile of TED among health care planners, health economists and clinicians, as the St Vincent's declaration had in diabetes, to improve the quality of care for patients with this condition (42).

\section{Conclusions}

In conclusion, TED has a negative and lasting impact on QOL and psychosocial function of affected patients. A key factor for poor QOL in these patients is the 
substandard care they receive for the disease. We can be optimistic that recent initiatives, including the Amsterdam declaration, to improve quality of care for patients with TED will help to improve their QOL.

\section{Declaration of interest}

The authors declare that there is no conflict of interest that would prejudice the impartiality of this scientific work.

\section{Funding}

Work of BV was partly supported by the National Institute for Health Research (NIHR). The views expressed in this publication are those of the authors and not necessarily those of the National Health Service, the NIHR or the Department of Health, United Kingdom.

\section{References}

1 Perros P, Neoh C \& Dickinson J. Thyroid eye disease. BMJ 2009 338 b560. (doi:10.1136/bmj.b560)

2 Bartalena L \& Tanda ML. Clinical practice. Graves' ophthalmopathy. New England Journal of Medicine 2009360 994-1001. (doi:10.1056/NEJMcp0806317)

3 Gerding MN, Terwee CB, Dekker FW, Koornneef L, Prummel MF \& Wiersinga WM. Quality of life in patients with Graves' ophthalmopathy is markedly decreased: measurement by the medical outcomes study instrument. Thyroid 19977 885-889. (doi:10. 1089/thy.1997.7.885)

4 Kahaly GJ, Hardt J, Petrak F \& Egle UT. Psychosocial factors in subjects with thyroid-associated ophthalmopathy. Thyroid 2002 12 237-239. (doi:10.1089/105072502753600205)

5 Kahaly GJ, Petrak F, Hardt J, Pitz S \& Egle UT. Psychosocial morbidity of Graves' orbitopathy. Clinical Endocrinology 200563 395-402. (doi:10.1111/j.1365-2265.2005.02352.x)

6 Egle UT, Kahaly GJ, Petrak F, Hardt J, Batke J, Best J \& Rothenbacher M. The relevance of physical and psychosocial factors for the quality of life in patients with thyroid-associated orbitopathy (TAO). Experimental and Clinical Endocrinology and Diabetes 1999107 (Supplement 5) S168-S171. (doi:10.1055/s0029-1212177)

7 Farid M, Roch-Levecq AC, Levi L, Brody BL, Granet DB \& Kikkawa DO. Psychological disturbance in graves ophthalmopathy. Archives of Ophthalmology 2005123 491-496. (doi:10. 1001/archopht.123.4.491)

8 Kulig G, Andrysiak-Mamos E, Sowinska-Przepiera E, Kulig J, Karakiewicz B, Brodowski J, Robaczyk M, Homa K, Letkiewicz M \& Syrenicz A. Quality of life assessment in patients with Graves' disease and progressive infiltrative ophthalmopathy during combined treatment with methylprednisolone and orbital radiotherapy. Endokrynologia Polska 200960 158-165.

9 Ponto KA, Pitz S, Pfeiffer N, Hommel G, Weber MM \& Kahaly GJ. Quality of life and occupational disability in endocrine orbitopathy. Deutsches Ärzteblatt International 2009106 283-289. (doi:10. 3238/arztebl.2009.0283)

10 Lee H, Roh HS, Yoon JS \& Lee SY. Assessment of quality of life and depression in Korean patients with Graves' ophthalmopathy. Korean Journal of Ophthalmology 201024 65-72. (doi:10.3341/ kjo.2010.24.2.65)

11 Abraham-Nordling M, Wallin G, Traisk F, Berg G, Calissendorff J, Hallengren B, Hedner P, Lantz M, Nyström E, Asman P, Lundell G, Törring O \& Thyroid Study Group of TT 96. Thyroid-associated ophthalmopathy; quality of life follow-up of patients randomized to treatment with antithyroid drugs or radioiodine. European Journal of Endocrinology 2010163 651-657. (doi:10.1530/EJE10-0475)
12 Bradley EA, Sloan JA, Novotny PJ, Garrity JA, Woog JJ \& West SK. Evaluation of the National Eye Institute visual function questionnaire in Graves' ophthalmopathy. Ophthalmology 2006113 1450-1454. (doi:10.1016/j.ophtha.2006.02.060)

13 Terwee CB, Gerding MN, Dekker FW, Prummel MF \& Wiersinga WM. Development of a disease specific quality of life questionnaire for patients with Graves' ophthalmopathy: the GO-QOL. British Journal of Ophthalmology $1998 \mathbf{8 2}$ 773-779. (doi:10.1136/bjo.82.7.773)

14 Terwee CB, Gerding MN, Dekker FW, Prummel MF, van der Pol JP \& Wiersinga WM. Test-retest reliability of the GO-QOL: a diseasespecific quality of life questionnaire for patients with Graves' ophthalmopathy. Journal of Clinical Epidemiology $1999 \mathbf{5 2}$ 875-884. (doi:10.1016/S0895-4356(99)00069-4)

15 Terwee CB, Dekker FW, Mourits MP, Gerding MN, Baldeschi L, Kalmann R, Prummel MF \& Wiersinga WM. Interpretation and validity of changes in scores on the Graves' ophthalmopathy quality of life questionnaire (GO-QOL) after different treatments. Clinical Endocrinology 200154 391-398. (doi:10.1046/j.13652265.2001.01241.x)

16 Terwee C, Wakelkamp I, Tan S, Dekker F, Prummel MF \& Wiersinga W. Long-term effects of Graves' ophthalmopathy on health-related quality of life. European Journal of Endocrinology 2002146 751-757. (doi:10.1530/eje.0.1460751)

17 Park JJ, Sullivan TJ, Mortimer RH, Wagenaar M \& Perry-Keene DA. Assessing quality of life in Australian patients with Graves' ophthalmopathy. British Journal of Ophthalmology 200488 75-78. (doi:10.1136/bjo.88.1.75)

18 Tehrani M, Krummenauer F, Mann WJ, Pitz S, Dick HB \& Kahaly GJ. Disease-specific assessment of quality of life after decompression surgery for Graves' ophthalmopathy. European Journal of Ophthalmology 200414 193-199.

19 Yeatts RP. Quality of life in patients with Graves ophthalmopathy. Transactions of the American Ophthalmological Society 2005103 $368-411$.

20 Bahmani-Kashkouli M, Pakdel F, Astaraki A, Hashemi M, Honarbakhsh Y \& Mirarmandehi B. Quality of life in patients with thyroid eye disease. Journal of Ophthalmic and Vision Research 20094 164-168.

21 Estcourt S, Vaidya B, Quinn A \& Shepherd M. The impact of thyroid eye disease upon patients' wellbeing: a qualitative analysis. Clinical Endocrinology 200868 635-639. (doi:10.1111/j.13652265.2007.03087.x)

22 Watt T, Hegedus L, Rasmussen AK, Groenvold M, Bonnema SJ, Bjorner JB \& Feldt-Rasmussen U. Which domains of thyroidrelated quality of life are most relevant? Patients and clinicians provide complementary perspectives Thyroid 200717 647-654. (doi:10.1089/thy.2007.0069)

23 Dickinson AJ, Vaidya B, Miller M, Coulthard A, Perros P, Baister E, Andrews CD, Hesse L, Heverhagen JT, Heufelder AE \& KendallTaylor P. Double-blind, placebo-controlled trial of octreotide longacting repeatable (LAR) in thyroid-associated ophthalmopathy. Journal of Clinical Endocrinology and Metabolism $2004 \mathbf{8 9}$ 5910-5915. (doi:10.1210/jc.2004-0697)

24 Prummel MF, Terwee CB, Gerding MN, Baldeschi L, Mourits MP, Blank L, Dekker FW \& Wiersinga WM. A randomized controlled trial of orbital radiotherapy versus sham irradiation in patients with mild Graves' ophthalmopathy. Journal of Clinical Endocrinology and Metabolism 200489 15-20. (doi:10.1210/jc.2003-030809) 25 Mourits MP, Bijl H, Altea MA, Baldeschi L, Boboridis K, Curro N, Dickinson AJ, Eckstein A, Freidel M, Guastella C, Kahaly GJ, Kalmann R, Krassas GE, Lane CM, Lareida J, Marcocci C, Marino M, Nardi M, Mohr CH, Neoh C, Pinchera A, Orgiazzi J, Pitz S, Saeed P, Salvi M, Sellari-Franceschini S, Stahl M, von Arx G \& Wiersinga WM. Outcome of orbital decompression for disfiguring proptosis in patients with Graves' orbitopathy using various surgical procedures. British Journal of Ophthalmology 2009 93 1518-1523. (doi:10.1136/bjo.2008.149302)

26 Charmaz K. The body, identy, and self: adapting to impairment. Sociological Quartely 199536 657-680. (doi:10.1111/j.15338525.1995.tb00459.x) 
27 Wiersinga WM, Prummel MF \& Terwee CB. Effects of Graves' ophthalmopathy on quality of life. Journal of Endocrinological Investigation 200427 259-264.

28 Coulter I, Frewin S, Krassas GE \& Perros P. Psychological implications of Graves' orbitopathy. European Journal of Endocrinology 2007157 127-131. (doi:10.1530/EJE-07-0205)

29 Ramos HE, Diehl LA, Camacho CP, Perros P \& Graf H. Management of Graves' orbitopathy in Latin America: an international questionnaire study compared with Europe. Clinical Endocrinology 200869 951-956. (doi:10.1111/j.1365-2265. 2008.03289.x)

30 Estcourt S, Hickey J, Perros P, Dayan C \& Vaidya B. The patient experience of services for thyroid eye disease in the United Kingdom: results of a nationwide survey. European Journal of Endocrinology 2009161 483-487. (doi:10.1530/EJE-09-0383)

31 Weetman AP \& Wiersinga WM. Current management of thyroidassociated ophthalmopathy in Europe. Results of an international survey. Clinical Endocrinology 199849 21-28. (doi:10.1046/j. 1365-2265.1998.00487.x)

32 Perros P, Baldeschi L, Boboridis K, Dickinson AJ, Hullo A, Kahaly GJ, Kendall-Taylor P, Krassas GE, Lane CM, Lazarus JH, Marcocci C, Marino M, Mourits MP, Nardi M, Orgiazzi J, Pinchera A, Pitz S, Prummel MF \& Wiersinga WM. A questionnaire survey on the management of Graves' orbitopathy in Europe. European Journal of Endocrinology 2006155 207-211. (doi:10.1530/eje.1. 02201)

33 Lazarus JH, Bartalena L, Marcocci C, Kahaly GJ, Krassas G \& Wiersinga WM. Glucocorticoid administration for Graves' hyperthyroidism treated by radioiodine. A questionnaire survey among members of the European Thyroid Association. Journal of Endocrinological Investigation 201033 409-413.

34 Prummel MF, Bakker A, Wiersinga WM, Baldeschi L, Mourits MP, Kendall-Taylor P, Perros P, Neoh C, Dickinson AJ, Lazarus JH, Lane CM, Heufelder AE, Kahaly GJ, Pitz S, Orgiazzi J, Hullo A, Pinchera A, Marcocci C, Sartini MS, Rocchi R, Nardi M, Krassas GE \& Halkias A. Multi-center study on the characteristics and treatment strategies of patients with Graves' orbitopathy: the first European Group on Graves' Orbitopathy experience. European Journal of Endocrinology 2003148 491-495. (doi:10.1530/eje.0. 1480491)

35 Sasim BerendschotTT IV, van Isterdael C \& Mourits MP. Planning health care for patients with Graves' orbitopathy. Graefe's Archive for Clinical and Experimental Ophthalmology $2008 \mathbf{2 4 6}$ 1315-1321. (doi:10.1007/s00417-008-0842-3)

36 Terwee CB, Dekker FW, Bonsel GJ, Heisterkamp SH, Prummel MF, Baldeschi L \& Wiersinga WM. Facial disfigurement: is it in the eye of the beholder? A study in patients with Graves' ophthalmopathy Clinical Endocrinology 200358 192-198. (doi:10.1046/j.13652265.2003.01695.x)

37 Bartalena L, Baldeschi L, Dickinson A, Eckstein A, KendallTaylor PMarcocci C et al. Consensus statement of the European Group on Graves' orbitopathy (EUGOGO) on management of GO. European Journal of Endocrinology 2008158 273-285. (doi:10. 1530/EJE-07-0666)

38 Bartley GB, Fatourechi V, Kadrmas EF, Jacobsen SJ, Ilstrup DM, Garrity JA \& Gorman CA. Long-term follow-up of Graves ophthalmopathy in an incidence cohort. Ophthalmology 1996 103 958-962.

39 Kendall-Taylor P. Current management of thyroid-associated ophthalmopathy. Clinical Endocrinology 199849 11-12. (doi:10. 1046/j.1365-2265.1998.00563.x)

40 Wiersinga WM. Management of Graves' ophthalmopathy. Nature Clinical Practice. Endocrinology and Metabolism 20073 396-404. (doi:10.1038/ncpendmet0497)

41 Graves' orbitopathy: improving outcomes for thyroid eye disease the Amsterdam Declaration. Thyroid 201020 351-352. (doi:10. 1089/thy.2010.1619)

42 Perros P \& Wiersinga WM. The Amsterdam Declaration on Graves' orbitopathy. Thyroid 201020 245-246. (doi:10.1089/ thy.2010.1618)

Received 24 February 2011

Accepted 2 March 2011 